\title{
Understanding Retinopathy of Prematurity: Update on Pathogenesis
}

\author{
José Carlos Rivera ${ }^{a}$ b Przemyslaw Sapieha ${ }^{b} \quad$ Jean-Sébastien Joyal ${ }^{a}$ \\ François Duhamel $^{\mathrm{a}, \mathrm{b}}$ Zhuo Shao $^{\mathrm{a}}$ Nicholas Sitaras $^{\mathrm{a}} \quad$ Emilie Picard $^{\mathrm{a}}$ \\ Ellen Zhou ${ }^{\mathrm{a}, \mathrm{b}}$ Pierre Lachapelle ${ }^{c}$ Sylvain Chemtob ${ }^{\mathrm{a}, \mathrm{b}}$ \\ a Department of Pediatrics, Ophthalmology and Pharmacology, Centre Hospitalier Universitaire Sainte-Justine \\ Research Center, ${ }^{b}$ Department of Ophthalmology, Maisonneuve-Rosemont Hospital Research Center, University \\ of Montreal, and 'Department of Ophthalmology/Neurology, McGill University-Montreal Children's Hospital \\ Research Institute, Montréal, Qué., Canada
}

\section{Key Words}

Retinopathy $\cdot$ Nitro-oxidative stress $\cdot$ Trans-arachidonic acids $\cdot$ Succinate $\cdot$ GPR91 $\cdot$ Semaphorin $3 \mathrm{~A}$ and $3 \mathrm{E} \cdot$ $\omega-3$ lipids

\begin{abstract}
Retinopathy of prematurity (ROP), an ocular disease characterized by the onset of vascular abnormalities in the developing retina, is the major cause of visual impairment and blindness in premature neonates. ROP is a complex condition in which various factors participate at different stages of the disease leading to microvascular degeneration followed by neovascularization, which in turn predisposes to retinal detachment. Current ablative therapies (cryotherapy and laser photocoagulation) used in the clinic for the treatment of ROP have limitations and patients can still have long-term effects even after successful treatment. New treatment modalities are still emerging. The most promising are the therapies directed against VEGF; more recently the use of preventive dietary supplementation with $\omega-3$ polyunsaturated fatty acid may also be promising. Other than pharmacologic and nutritional approaches, cell-based strategies for vascular repair are likely to arise from advances in regenerative medicine using stem cells. In addition to all of these,
\end{abstract}

a greater understanding of other factors involved in regulating pathologic retinal angiogenesis continues to emerge, suggesting potential targets for therapeutic approaches. This review summarizes an update on the current state of knowledge on ROP from our and other laboratories, with particular focus on the role of nitro-oxidative stress and notably trans-arachidonic acids in microvascular degeneration, semaphorin 3 operating as vasorepulsive molecules in the avascular hypoxic retina and in turn impairing revascularization, succinate and its receptor GPR91 in neuron-mediated retinal neovascularization, and $\omega-3$ lipids as modulators of preretinal neovascularization. Copyright $\odot 2011$ S. Karger AG, Basel

\section{Introduction}

Retinopathy of prematurity (ROP) has been recognized since 1942 as a blinding disease of premature infants [1]. In more than half a century of intense clinical and laboratory research, great advancements have been

Presented at the International Symposium 'Recent Advances in Neonatal Medicine', Würzburg, 2011.

\section{KARGER}

Fax +41613061234

E-Mail karger@karger.ch

www.karger.com
(C) 2011 S. Karger AG, Basel

$1661-7800 / 11 / 1004-0343 \$ 38.00 / 0$

Accessible online at:

www.karger.com/neo
Sylvain Chemtob, MD, PhD, FRCPC

Department of Pediatrics, Ophthalmology and Pharmacology

Centre Hospitalier Universitaire Sainte-Justine Research Center

3175, Chemin Côte Sainte-Catherine, Montréal, QC H3T 1C5 (Canada)

Tel. +1 514345 4931, ext. 2978, E-Mail sylvain.chemtob@ umontreal.ca 
made in elucidating its pathogenesis and in developing effective therapies for severe stages of ROP. The results of these efforts have yielded cryotherapy and laser photocoagulation, two approaches that consist of destroying the portion of the avascular retina which is the source of growth factors that promote neovascularization. However, these procedures only partially reduce the incidence of blindness in infants with severe late-stage disease, and do not markedly affect visual acuity [2]. Despite the recent demonstration that anti-vascular endothelial growth factor (VEGF) therapy is an effective antiangiogenic therapy for severe ROP [3], long-term defects in visual acuity, disorders in color discrimination and appropriate adaptation to darkness, remain a concern.

The oxygen-induced retinopathy (OIR) animal model of ROP $[4,5]$ has been very helpful to understand numerous aspects of ROP, including the role of oxidant stress, various growth factors such as VEGF and insulin-like growth factor (IGF) in vascular development, and structure-functional anomalies, as these corresponded to observations in humans. In this review we plan to focus on new and relevant observations regarding nitro-oxidative mediators, notably trans-arachidonic acids (TAAs) in microvascular degeneration, on semaphorin $3 \mathrm{~A}$ and $3 \mathrm{E}$ (Sema3A and 3E) identified as vasorepulsive molecules in the avascular hypoxic retina which impairs revascularization, on succinate and its receptor GPR91 in neuronmediated retinal neovascularization, and on $\omega-3$ lipids that modulate preretinal neovascularization. It should be highlighted that this is not a comprehensive review on ROP pathophysiology, which has recently been reported $[6,7]$.

\section{Pathophysiology of ROP}

The retinal blood vessel development in humans commences around 16 weeks of gestation in a central-to-peripheral wave at a rate of about $0.1 \mathrm{~mm} /$ day [8]. The nasal retina is vascularized by 36 weeks' gestation and the temporal retina around 40 weeks. Because retinas of premature infants are incompletely vascularized, ROP incidence and severity are directly proportional to the degree of prematurity. The development of ROP progresses through two phases. The first phase begins when retinal vascular growth ceases after premature birth. During this time the vessels are particularly vulnerable to injury and may be obliterated by any number of stressors including the amount of oxygen supply, the suppression of vasoproliferation due to decreased VEGF and the scarcity in cytoprotective factors, notably IGF. Premature infants are exposed to higher oxygen tension after birth compared to that in utero, which leads to a downregulation of the major hypoxia-triggered VEGF, resulting in vasoobliteration of the developing retinal capillaries. This is one of the first events in the development of ROP.

This relatively vascular-depleted retina which becomes increasingly hypoxic by an increased metabolic demand of the developing retina triggers the vasoproliferative or second phase of ROP. In this phase, an overproduction of hormones and growth factors to ensure adequate perfusion to the now hypoxic retina takes place; in particular, VEGF, but also growth hormones, including IGF-1 are produced. These factors influence proteins of the extracellular matrix, such as vitronectin, fibronectin and fibrinogen, to deposit adhesive fibrins and induce growth, differentiation and migration on endothelial cells [9]. The formation of these new vessels is anarchic and excessive resulting in invasion of the vitreous, wherein traction on the retina and bleeding can occur. This critical stage of ROP occurs most frequently around 3334 weeks postconceptionally [10].

ROP is not only a vascular disorder, but is also associated with a number of functional visual deficits. Although peripheral functional visual disorders have been described in ROP, the most pronounced deficits arise from central disorders of the retina, as attested by defective cone and rod functions $[11,12]$; similar observations have been made in the OIR model of ROP [13]. A marked involution of the central choroid and choriocapillaris, the exclusive circulatory supply of nutrients and oxygen to the outer retina, was recently reported as an important contributor to central photoreceptor compromise in the OIR/ROP [14]; accordingly, preservation of the choroid conserved photoreceptor integrity. Hence, these observations unveil an unprecedented central choroidal involution in OIR; interestingly, a similar albeit limited observation has been made in human ROP [15].

\section{Risk Factors of ROP: Increased Oxygenation}

Numerous factors participate in the genesis of ROP. Although some studies have reported that exposure to multiple gestation, apnea, race, light, anemia, sepsis, prolonged mechanical ventilation and multiple transfusions are risk factors for ROP [16], the precise individual role of these factors in the development of the disease is not well established. On the other hand, low birth weight and gestational age as well as high postnatal oxygenation (dis- 
cussed below) have consistently been shown to increase the risk of ROP.

The intrinsic property of many organs to maintain blood flow constant over a range of perfusion pressures and oxygen tensions to meet metabolic demand of the tissues is termed autoregulation. Preterm infants who suffer complications of prematurity exhibit total absence of autoregulation of ocular blood flow resulting in an exaggerated delivery of potentially toxic oxygen to the retina when they are exposed to oxygen supplementation to overcome respiratory insufficiency [17]. This relative inability of the neonate to control oxygen delivery to the retina is largely due to high perinatal levels of prostaglandins (such as $\mathrm{PGD}_{2}$ and $\mathrm{PGE}_{2}$ ) and nitric oxide (NO) that profoundly influence vasomotor tone and override the autoregulatory response $[18,19]$.

The rise in carbon dioxide tension (hypercapnia) is another factor significantly contributing to the disruption of regulation of retinal and choroidal blood flow in infants born prematurely. Both acute and sustained hypercapnias markedly increase retinal and choroidal blood flow in premature infants. The acute rise in ocular blood flow in response to hypercapnia is largely $\mathrm{PGE}_{2}$-dependent. During sustained hypercapnia, this increase in $\mathrm{PGE}_{2}$ induces expression of endothelial $\mathrm{NO}$ synthase (eNOS), which releases NO and in turn mediates the delayed carbon dioxide-induced rise in ocular hemodynamics and further curtails ocular blood flow autoregulation [20]. This marked induction in ocular hyperemia is clinically relevant, since hypercapnia has been associated with ROP in humans and in OIR in experimental animals [21].

\section{Vaso-Obliteration}

In response to the ensuing retinal hyperoxia, the particularly vulnerable endothelial cells at the vascular front degenerate, producing vasoconstriction of immature vessels and consequent destruction of the vascular bed. A number of factors participate in the endothelial cytotoxicity that leads to the vaso-obliteration phase: (1) oxygendependent suppression of growth factors such as VEGF and erythropoietin through stabilization of hypoxia-inducible factor [22, 23]; (2) decreased expression of the maternal and nutrition-dependent factor IGF-1 [24]; (3) reduced presence of anti-inflammatory factors which suppress production of excessive cytotoxic concentrations of TNF- $\alpha$ in the developed retina [25]; (4) inability of the newborn to autoregulate oxygen delivery [26]; (5) in- creased generation of reactive oxygen species (ROS) and their peroxidation products, notably thromboxane $A_{2}$, platelet-activating factor (PAF) and lysophosphatidic acid (LPA), along with a reduced concentration of major components of the antioxidant systems in the neonates, including heme oxygenase-1, metallothionein, $\mathrm{Cu}-\mathrm{Zn}$ superoxide dismutase, catalase, vitamins $\mathrm{C}$ and $\mathrm{E}$, and glutathione peroxidase [27]; (6) nitrative stress that also results in an increased production of TAAs that contributes to retinal vascular degeneration [28], and (7) increased vulnerability of the neuroretinal endothelium to cytotoxic agents such as prostanoids and isoprostanes derived by oxidant stress and lipid peroxidation due to high content of polyunsaturated fatty acids in the immature retina [29].

\section{Nitro-Oxidative Stress, and Lipid Oxidation and Nitration}

ROS and oxidative stress are known to contribute to the retinal vaso-obliteration in ROP. NO, a complex molecule that exerts both protective and proangiogenic properties in the eye, can have differential effects in OIR depending on the redox state of the retina. In vivo for example, we showed that eNOS expression and activity is increased when the redox state is shifted toward an oxidative environment $[30,31]$. Under these conditions, $\mathrm{NO}$ can react with ROS affecting the cell function by a process named nitro-oxidative stress. As a result, generation of nitrites, nitrates and peroxynitrite, and protein tyrosine nitration are enhanced increasing retinal microvascular degeneration [32]. Genetic ablation [33] and pharmacologic inhibition of eNOS [34], as well as the use of antioxidants [35, 36], has been shown to attenuate hyperoxia-induced retinal microvascular degeneration, demonstrating the importance of nitro-oxidative stress in ROP.

Lipid peroxidation of cell membranes secondary to inadequate oxygen tension is pivotal to the pathogenesis of ROP and, together with nitrative stress, among the most toxic consequences of increased ROS. Polyunsaturated fatty acids (PUFAs) of membrane phospholipids are common targets for peroxidation, resulting in loss of cell membrane function and structural integrity. The retina is highly susceptible to lipid peroxidation, as it is composed of lipids with elevated levels of PUFAs such as docosahexaenoic acid (DHA), cis-arachidonic acid (AA) and choline phosphoglyceride.

Prostanoids are synthesized from AA by the sequential action of phospholipase $\mathrm{A}_{2}\left(\mathrm{PLA}_{2}\right)$ and cyclooxygenase (COX) triggered by oxidant stress and peroxidation. 
Fig. 1. The effects of oxidant stress on premature retinal vasculature. The premature retina is relatively deficient in antioxidants. Consequently, oxidant stress is more likely to induce peroxidation and nitration that is cytotoxic to retinal microvasculature. Downstream mediators of peroxidation, notably the phospholipids PAF and LPA, the nonenzymatically derived prostanoids, isoprostanes, and nitration products (of particular relevance here are the TAAs), are all cytotoxic to retinovascular endothelium, causing vaso-obliteration. $\mathrm{PGS}=\mathrm{PG}$ synthase; $\mathrm{TXS}=$ thromboxane synthase.

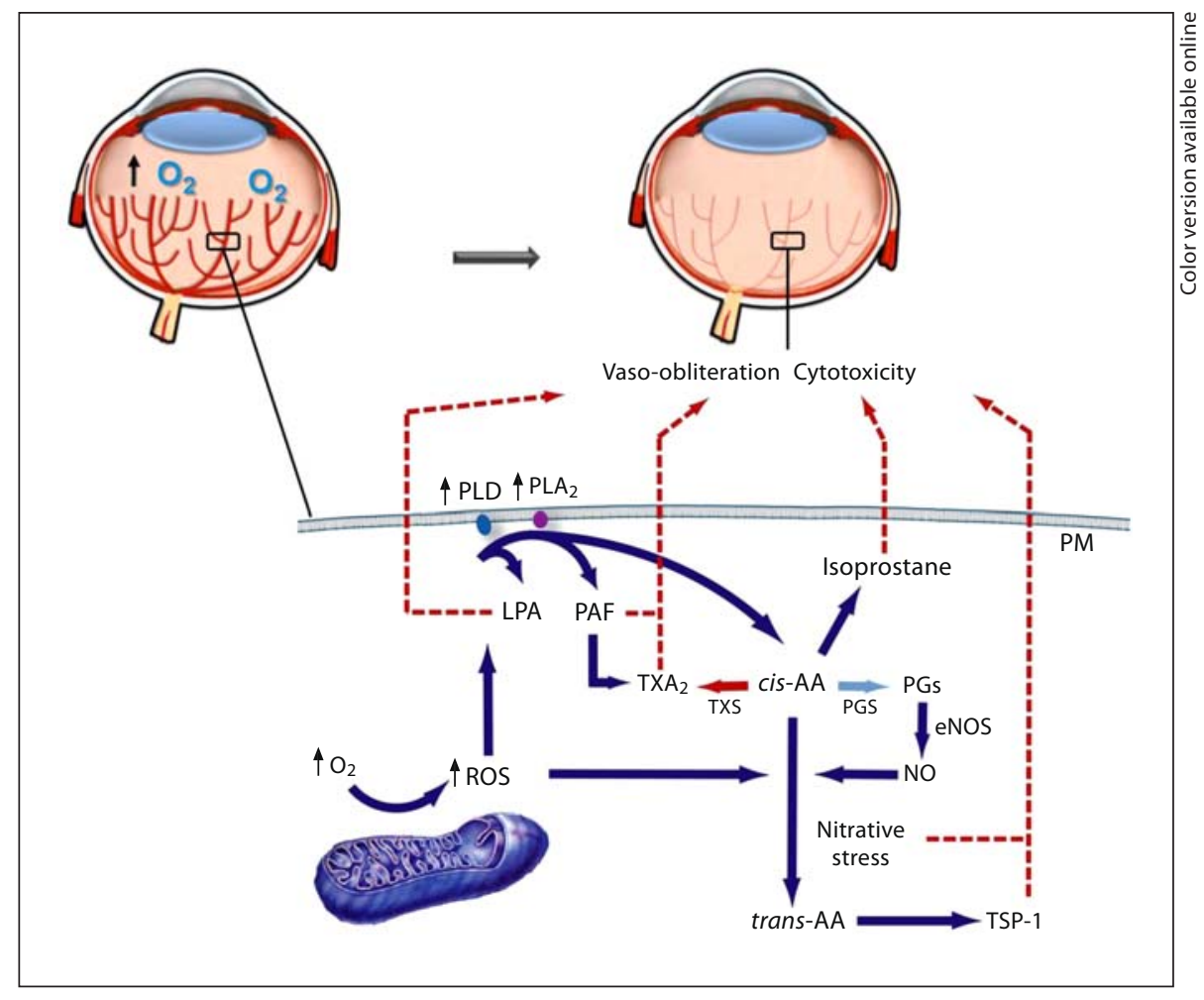

The accumulation of peroxides eventually favors thromboxane $\left(\mathrm{TXA}_{2}\right)$ production over that of prostaglandins. $\mathrm{TXA}_{2}$ is a potent vasoconstrictor as well as a cytotoxic agent in microvessels [37]. Consistent with these events having a role in ROP, inhibitors of COX and $\mathrm{TXA}_{2}$ synthase selectively curtail oxygen-induced retinal vasoobliteration in rodents [37]. In contrast to prostaglandins produced by COX, isoprostanes are formed nonenzymatically in situ from the peroxidation of AA and then released by phospholipases; they exceed the production of prostaglandins under oxidizing conditions. Isoprostanes may contribute to microvascular injury in ROP, as they are indirectly cytotoxic, since they trigger the production of $\mathrm{TXA}_{2}$ [38] (fig. 1). Nitrative stress results in cis- to trans-isomerization of AA (TAA), and this was recently shown to contribute to retinal vascular degeneration in a mouse model of ROP [28]. Circulating levels of plasma TAA are increased in oxygen-induced microvascular degeneration and are known to be associated with induction of nitrative stress [39]. More specifically, TAA formation is abrogated in mice treated with NOS inhibitors and in mice deficient in eNOS [34] (fig. 1). The endothelial cytotoxicity induced by TAA results from the formation of the anti-angiogenic and proapoptotic thrombospondin-1 (TSP-1) [34].
Other lipids generated during peroxidation are important proinflammatory mediators, including LPA and PAF. Choline phosphoglycerides are the precursors of PAF. Constitutive levels of PAF are maintained by the de novo pathway to ensure normal housekeeping cellular function. Otherwise, PAF is abundantly generated under oxidative stress by the remodeling pathway and calciumdependent activation of cytosolic PLA 2 . In ROP, AAs are cleaved off from membrane phospholipids (by cPLA ${ }_{2}$ ) to yield lysophospholipids, which in turn can be acetylated and converted to PAF [40]. Both the vasomotor and cytotoxic effects of PAF in the premature infant are mediated to a large extent by $\mathrm{TXA}_{2}[41,42]$. Thus, PAF, which is generated concomitantly with $\mathrm{TXA}_{2}$ during oxidant stress and amplifies formation of $\mathrm{TXA}_{2}$, contributes to retinal vaso-obliteration in ischemic retinopathies (fig. 1). Along the same lines, LPA is also released from lysophosphatidylcholine by the action of lysophospholipase $\mathrm{D}$ and can partake in retinal inflammation leading to microvascular cytotoxicity [43].

\section{Insulin-Like Growth Factor-1}

Other factors present in utero that partake in normal fetal development are deficient in preterm infants at risk for ROP. IGF-1 is a polypeptide protein hormone essential 
for fetal development at all stages of pregnancy [44]. Plasma levels of IGF-1 rise with gestational age, particularly during the third trimester of pregnancy [45]. Premature infants suffer a decrement in the serum levels of IGF-1 due to loss of placenta and sufficient nutrient supply in utero [46].

The association between low serum levels of IGF- 1 and ROP was explored in the elegant works of Smith and colleagues $[47,48]$ who demonstrated that a deficiency in growth hormone and downstream IGF-1 caused retardation in retinal vessel growth akin to patterns noted in premature babies with ROP. Interestingly, in human subjects, low serum levels of IGF-1 directly correlate with the severity of ROP [49], and IGF-1-binding protein IGFB3 was also found to be decreased in premature infants contributing with retinal vessels depletion [50].

IGF-1 modulates vessel survival by controlling the VEGF-induced activation of Akt and ERK1/2 mitogenactivated protein kinase - essential for endothelial cell proliferation $[24,48]$. In this regard, IGF-1 appears to act as a permissive factor for VEGF-dependent endothelial growth and survival such that VEGF alone would be insufficient to induce the exaggerated angiogenesis associated with ROP and other proliferative retinopathies. To this respect, clinical trials are being undertaken to address the merits of treatment with IGF-1 at an early stage to prevent the vaso-obliteration in the premature infants. So far, these preliminary studies have shown that infusion of fresh frozen plasma, which is a source of exogenous IGF-1 [51], or the intravenous administration of recombinant protein complex of rhIGF-1 and rhIGFBP-3 in premature infants increase serum IGF-I levels to the levels normally found in utero at the corresponding gestational age [52].

Experimental animals, notably mice that received exogenous recombinant human IGF-I, exhibited higher IGF-I levels with weight gain, matured faster and developed less OIR [53]. These findings in mice are the first to support the notion that higher availability of (endogenous or exogenous) IGF-I reduces OIR risk, and support the notion that ROP may be preventable.

\section{Semaphorins}

Anatomical studies since the fifteenth century have shown that vascular and neural networks are architecturally paralleled and interact physically. Nevertheless, only in the last decade has it come to light that blood vessels and nerves are guided through the body by the same families of cues. One of the most versatile examples of these families is the class 3 semaphorins (Sema3), first identified as glycoproteins that negatively mediate neuronal guidance by binding to neuropilin and repelling neurons away from the site production [54]. Sema3 are now regarded as key regulators of cellular processes such as endothelial and tumor cell survival, proliferation, apoptosis, and migration [55]. Considered potent inhibitors of tumor growth and vessel density, Sema3 acts primarily by inhibiting the cell motility and migration of endothelial cells by inducing the collapse of the actin cytoskeleton via neuropilins and plexins. Semaphorins such as Sema3A and Sema3E bind, respectively, to neuropilin and plexin-D1.

The role of semaphorins in the pathophysiology of ROP was recently investigated. Using knockdown of the retinal ganglion cell Sema3A, our laboratory demonstrated for the first time that in response to hypoxia, retinal neurons secrete neuronal guidance cue Sema3A, which acts as a chemical barrier to repulse new vessels and in turn prevent revascularization of hypoxic retinal tissue (fig. 2) [56]. An important regulator of Sema3A generation was found to be the proinflammatory cytokine interleukin-1 $\beta$ (IL-1 $\beta)$. In a somewhat complementary paradigm, Sema3E arising from neurons was also found to suppress anarchic extraretinal vascular outgrowth without affecting retinal vascular regeneration in the OIR model [57]. Together, these observations uncover major roles for semaphorins in governing the guidance of retinal vascular development.

\section{Neovascularization: Novel Mediators}

\section{Succinate and Its Receptor, GPR91}

As a result of vaso-obliteration, the retina attempts to reinstate adequate levels of oxygen and nutrients to the hypoxic/ischemic tissue; in this process, it orchestrates neovascularization. Factors that partake in this neovascularization include VEGF, fibroblast growth factor, hepatocyte growth factor, platelet-derived growth factor and erythropoietin [58]. We recently explored the mechanisms involved in regulating expression of angiogenic factors by exploring the role of major intermediary energy metabolites, notably the Krebs cycle intermediate, succinate. In this respect, it was shown that succinate levels, which increase during hypoxic conditions, induce a vasoproliferation response in the retina by activating its $\mathrm{G}$ protein-coupled receptor GPR91 [59]. This receptor, expressed particularly in highly vascularized tissues [60], was also abundantly expressed in retinal ganglion cells [59]. GPR91 exerted control in the expression of numerous major angiogenic factors, such as VEGF and angiopoietin 1 and 2, and suppressed antiangiogenic thrombo- 


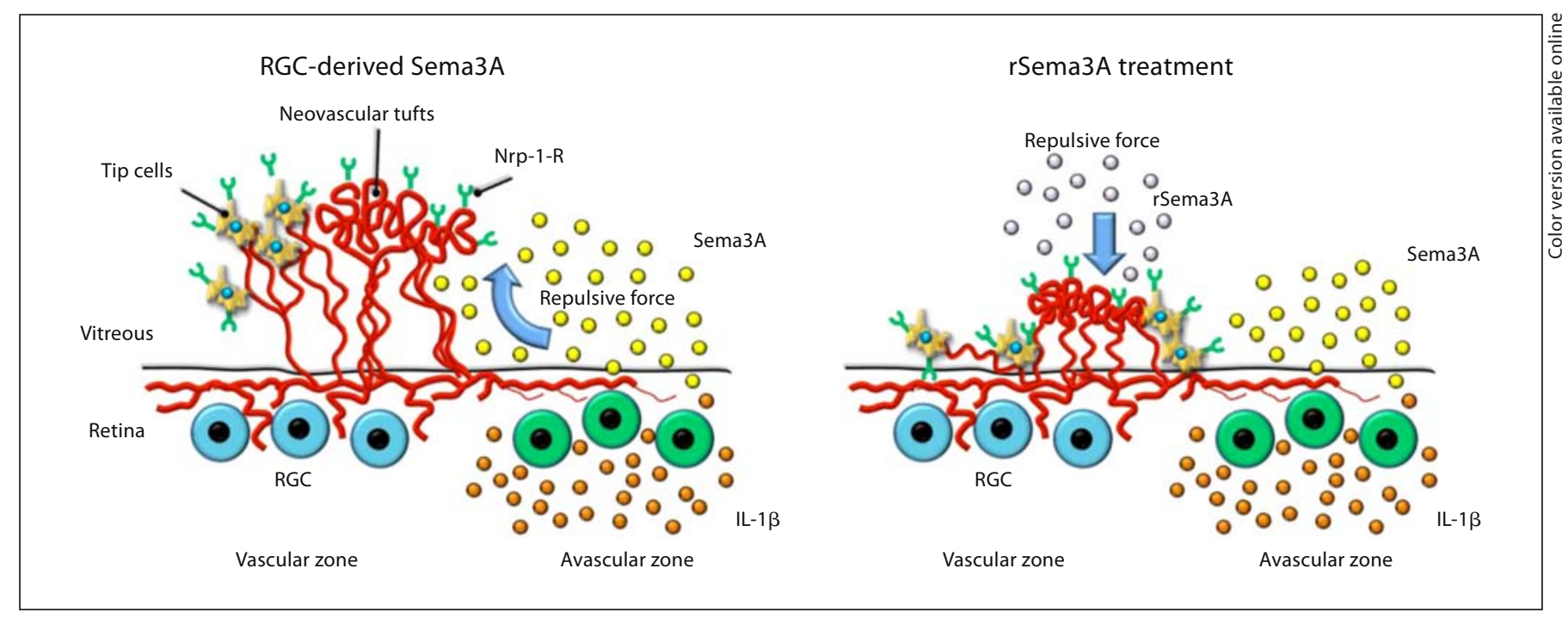

Fig. 2. Role of Sema3A as vasorepulsive molecules in the retina. Ischemic neurons in the avascular zones produce Sema3A secondary to inflammatory stress (IL-1 $\beta$ ). Pathologic neovascular tufts are enriched in neuropilin-1 receptor (Nrp-1-R). Retinal ganglion cell (RGC)-derived Sema3A impedes revascularization and repels neovessels away from the avascular neural retina towards the vitreous (left), whereas intravitreal rSema3A (injected) prevents preretinal invasion of pathological neovessels (right). spondin-1. Genetic disruption in GPR91 expression or in retinal ganglion cell development interfered with retinal angiogenesis during development as well as in the OIR model of ROP (fig. 3). These unprecedented observations indicated that hypoxia-driven metabolic changes in neurons contribute in attempting to restore vascular supply in the OIR model by elevating the formation of intermediate metabolites such as succinate. These novel findings provide innovative therapeutic avenues aimed at restoring sufficient vascular supply after neural ischemic insult.

\section{Inflammatory Mediators}

Inflammation is a complex, highly regulated sequence of events that can be provoked by a variety of stimuli. It is the primary process through which tissues, including the eye, repair damage and defend themselves against abnormal conditions. However, excess inflammation is pathological and can result in tissue destruction, leading to visual dysfunction and blindness. The role of inflammation in ROP has been poorly investigated; however, some evidence in humans point to its contribution in ROP. For instance, Sood et al. [61] found that in patients who later developed ROP, there were higher systemic levels of IL-6 and C-reactive protein, and lower concentrations of neurotrophin- 4 and IL-17, compared to controls on postnatal days $0-3$; whereas on postnatal days 7-21 there were higher levels of IL-18 compared to controls.
In another study, Sato et al. [62] analyzed the vitreous levels of 27 cytokines in eyes with ROP and found higher levels of several cytokines in eyes with ROP, including IL-6, IL-7, IL-10, IL-15, eotaxin, fibroblast growth factor, granulocyte colony-stimulating factor, granulocytemacrophage colony-stimulating factor, interferon- $\gamma$-inducible protein-10 and (mostly) VEGF. Studies in our laboratory showed that COX-2, an early gene product of inflammation, contributes to preretinal neovascularization in ischemic retinopathies through generation of $\mathrm{PGE}_{2}$ which in turn acts on its $\mathrm{EP}_{3}$ receptor $[63,64]$.

\section{$\omega$-3 Lipids}

$\omega-3$ lipids [notably DHA and eicosapentaenoic acid (EPA)] have been found to exert a number of beneficial biological properties such as diminished triglycerides, cytoprotection including of neural tissue, decreased oxidant stress and (most noteworthy) decreased inflammation $[65,66]$. The retina contains the highest concentration of DHA of all tissues [67]. Premature newborns are relatively deficient in $\omega-3$ lipids, and supplementation with DHA and EPA has been found to improve visual acuity [68]. The efficacy of $\omega-3$ lipids on ROP/OIR has recently been reported. In mouse pups of dams fed $\omega-3$ supplements starting on postnatal day 1 , decreased oxygen-induced vaso-obliteration and neovascularization were observed [25]. The supplementation with $\omega-3$ 


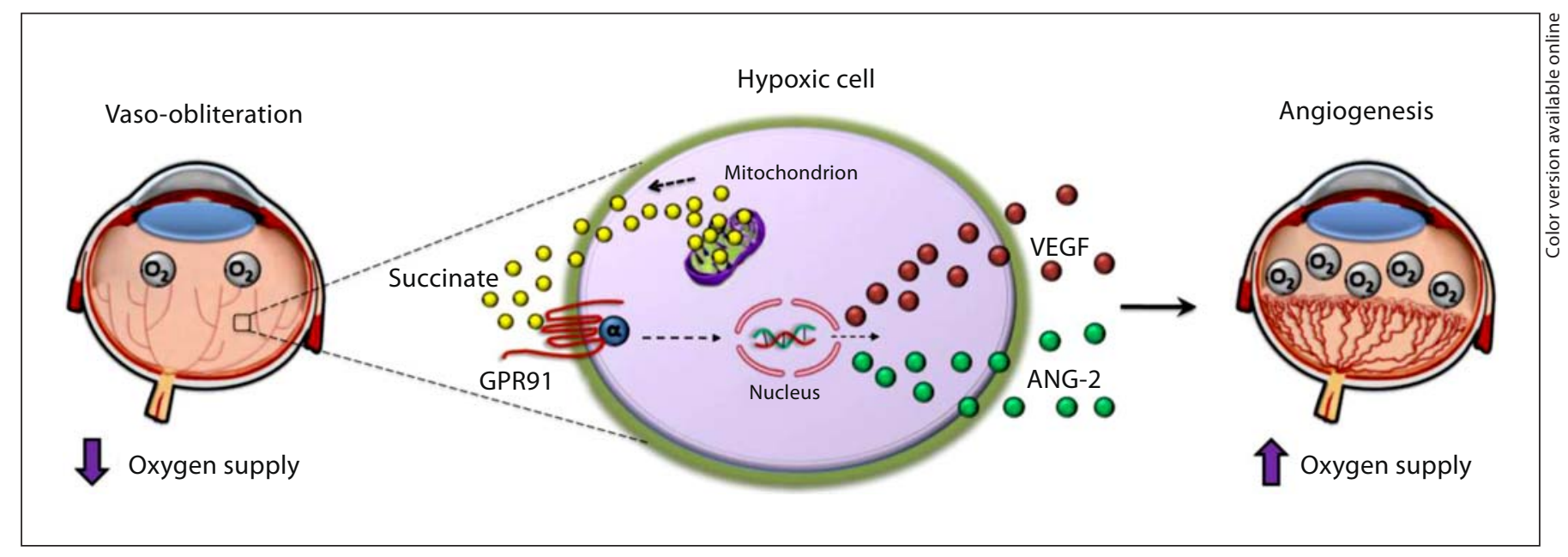

Fig. 3. The proangiogenic effects of the metabolite succinate in ROP. Hyperoxia induces microvascular degeneration in the retina with consequent decrement in the oxygen supply that stimulates the production and accumulation of succinate. Through its actions on its receptor, GPR91, which is present on retinal ganglion cells, succinate induces production of proangiogenic factors, par- ticularly VEGF and angiopoietin 2 (ANG-2), which trigger neovascular formation. This new vessel growth attempts to restore oxygen supply to the hypoxic retina; however, in ROP this compensatory vascular expansion is exaggerated and penetrates the vitreous. lipids led to increased formation of cytoprotective and anti-inflammatory metabolites, notably neuroprotectins and resolvins which exerted their effects in part by suppressing TNF- $\alpha$. The same group of investigators also uncovered that 5-lipoxygenase metabolites of DHA, specifically 4-hydroxy-DHA, mediate the antivasoproliferative effects of DHA independently of VEGF formation, but dependent of PPAR- $\gamma$ activation [69]. In line with these animal observations, $\omega-3$ supplementation to preterm infants was found to reduce the risk of severe ROP [70]. Hence, supplementation with DHA/EPA appears to improve visual acuity and protect against the development of ROP [71]; however, the latter needs to be confirmed.

\section{Therapies and Prevention of ROP}

\section{Therapies}

Ablative therapies including cryotherapy and laser photocoagulation are the procedures most commonly used in the clinic for the treatment of ROP (fig. 4). These treatments destroy tissue in the avascular retina including those that generate VEGF which promotes aberrant preretinal neovascularization. Despite this form of therapy, visual acuity remains largely unaffected and, as expected, peripheral vision is inevitably lost [2].

\section{Anti-VEGF Therapy}

A promising strategy to counter ROP is the use of the anti-VEGF therapy (fig. 4). Bevacizumab, a VEGF-specific neutralizing antibody is currently used for treatment of several diseases including diabetic retinopathy and macular degeneration. Until recently, bevacizumab was used for ROP in the absence of randomized trials [72]; timing (stage/zone of ROP), dose (0.4-12.5 mg intravitreal) and frequency of administration of bevacizumab, as well as cotreatment with photocoagulation, varied tremendously among reports. Nonetheless, there were generally favorable outcomes (controlled progressive neovascularization) in most reports. A prospective randomized double-blind trial of bevacizumab was recently reported and revealed that the recurrence rate of preretinal neovascularization was significantly greater in laser-treated patients than bevacizumab-treated ones exhibiting proliferative retinopathy in the central zone 1 [3]. Moreover, revascularization of the peripheral retina occurred as expected in a normal subject, while conventional laser therapy led to destruction of the peripheral retina. Despite these promising beneficial effects of bevacizumab in the treatment of ROP, additional studies are needed to determine the optimum dosages, timing of administration, frequency and evaluation of possible collateral effects, especially for neurodevelopment. 
Fig. 4. Summary of the current concepts in ROP. At birth, premature infants are deficient in several maternally derived factors such as $\omega-3$ PUFAs and IGF-1 that are essential for healthy blood vessel development. Moreover, when the premature are mechanically ventilated to overcome pulmonary insufficiencies, the excessive supplemental oxygen contributes to retinal vascular obliteration due to oxidant stress and suppression of oxygen-regulated proangiogenic factors such as VEGF and erythropoietin (Epo). Following the initial phase of vascular dropout, a second phase of compensatory and destructive neovascularization results and is driven by hypoxia-induced angiogenic factors, such as VEGF and metabolite factors (succinate). Vasorepulsive molecules (Sema3A) also operate, avoiding the revascularization to the avascular zones. Current therapeutic interventions rely on invasive procedures such as laser photocoagulation, whereby affected areas of the retina are cauterized. A number of future treatments, including anti-VEGF therapy and the use of antioxidants, are currently being evaluated.

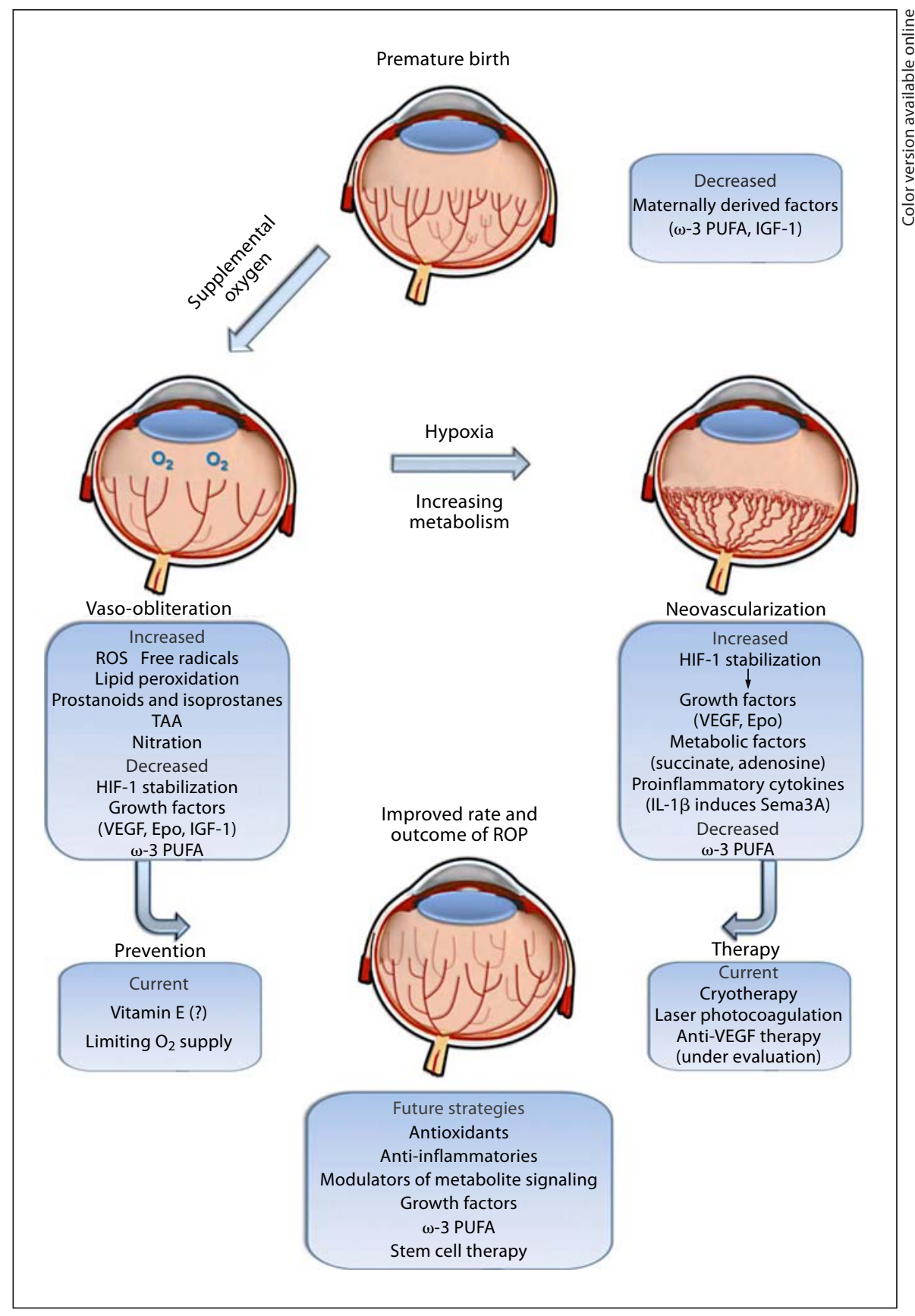

\section{Prevention}

The development of preventive and less destructive therapies for ROP such as (1) restricting tissue oxygenation to reduce oxygen toxicity [73]; (2) nutritional supplements including the use of antioxidants such as vitamin E [74] and vitamin C [75] that decrease lipid peroxidation and help maintain membrane integrity; (3) the use of $\omega-3$ fatty acids [70], and (4) the potential administration of cytoprotective growth factors such as erythropoietin and/or IGF-1 could be more desirable than treatment of an established disorder. However, although promising, other than limiting post-natal hemoglobin-oxygen saturation, the other modalities remain speculative at this point (fig. 4). 


\section{Conclusion}

Preretinal neovascularization in ROP is the consequence of a progressive destruction of the retinal microvasculature. A better understanding of the underlying mechanisms implicated in extraretinal neovascularization, revascularization and vascular guidance should identify new targets and foster the development of new therapeutic approaches. Along these lines, a more profound elucidation of the complex interplay of inflammatory mediators is required. Other than pharmacologic and nutritional strategies, cell-based strategies for vascular repair are likely to emerge from advances in regenerative medicine using stem cells [76]. Finally, although recent advances in clinical trials and basic science research have led to improved knowledge of the pathophysiology of ROP, additional preventive strategies are clearly needed.

\section{Acknowledgements}

J.C. Rivera is supported by the Heart and Stroke Foundation of Canada and the Canadian Stroke Network. J.-S. Joyal is a recipient of the Canadian Child Health Clinician Scientist Program, a CIHR training initiative. F. Duhamel, Z. Shao and N. Sitaras are recipients of a CIHR studentship. E. Picard is a recipient of a Fond de la Recherche en Santé du Québec fellowship award. P. Sapieha holds a Canada Research Chair (Retinal Cell Biology) and is supported by grants from the CIHR. S. Chemtob holds a Canada Research Chair (Vision Science) and the Leopoldine Wolfe Chair in translational research in age-related macular degeneration and is supported by grants from the CIHR and Fond de la Recherche en Santé du Québec.

\section{Disclosure Statement}

The authors report no conflicts of interest. The authors alone are responsible for the content and writing of the paper.

\section{References}

1 Terry TL: Extreme prematurity and fibroplastic overgrowth of persistent vascular sheath behind each crystalline lens. I. Preliminary report. Am J Ophthalmol 1942;25: 203-204.

2 Chen J, Smith LE: Retinopathy of prematurity. Angiogenesis 2007;10:133-140.

-3 Mintz-Hittner HA, Kennedy KA, Chuang AZ; BEAT-ROP Cooperative Group: Efficacy of intravitreal bevacizumab for stage $3+$ retinopathy of prematurity. $\mathrm{N}$ Engl J Med 2011;364:603-615.

4 Penn JS, Tolman BL, Henry MM: Oxygeninduced retinopathy in the rat: relationship of retinal nonperfusion to subsequent neovascularization. Invest Ophthalmol Vis Sci 1994;35:3429-3435.

-5 Smith LE, Wesolowski E, McLellan A, Kostyk SK, D’Amato R, Sullivan R, D'Amore PA: Oxygen-induced retinopathy in the mouse. Invest Ophthalmol Vis Sci 1994;35: 101-111.

-6 Sapieha P, Joyal JS, Rivera JC, KermorvantDuchemin E, Sennlaub F, Hardy P, Lachapelle P, Chemtob S: Retinopathy of prematurity: understanding ischemic retinal vasculopathies at an extreme of life. J Clin Invest 2010;120:3022-3032.

7 Sapieha P, Hamel D, Shao Z, Rivera JC, Zaniolo K, Joyal JS, Chemtob S: Proliferative retinopathies: angiogenesis that blinds. Int J Biochem Cell Biol 2010;42:5-12.

$\checkmark 8$ Ashton N: Retinal angiogenesis in the human embryo. Br Med Bull 1970;26:103-106.

-9 Pollan C: Retinopathy of prematurity: an eye toward better outcomes. Neonatal Netw 2009;28:93-101.
10 Palmer EA, Flynn JT, Hardy RJ, Phelps DL, Phillips CL, Schaffer DB, Tung B: Incidence and early course of retinopathy of prematurity. The Cryotherapy for retinopathy of Prematurity Cooperative Group. Ophthalmology 1991;98:1628-1640.

-11 Siatkowski RM, Dobson V, Quinn GE, Summers CG, Palmer EA, Tung B: Severe visual impairment in children with mild or moderate retinal residua following regressed threshold retinopathy of prematurity. J AAPOS 2007; 11:148-152.

12 Fulton AB, Hansen RM, Petersen RA, Vanderveen DK: The rod photoreceptors in retinopathy of prematurity: an electroretinographic study. Arch Ophthalmol 2001; 119:499-505.

13 Dorfman AL, Cuenca N, Pinilla I, Chemtob S, Lachapelle P: Immunohistochemical evidence of synaptic retraction, cytoarchitectural remodeling, and cell death in the inner retina of the rat model of oxygen-induced retinopathy (OIR). Invest Ophthalmol Vis Sci 2011;52:1693-1708.

14 Shao Z, Dorfman AL, Seshadri S, Djavari M, Kermorvant-Duchemin E, Sennlaub F, Blais M, Polosa A, Varma DR, Joyal JS, Lachapelle P, Hardy P, Sitaras N, Picard E, Mancini J, Sapieha P, Chemtob S: Choroidal involution is a key component of oxygen induced retinopathy. Invest Ophthalmol Vis Sci 2011, Epub ahead of print.

15 Vrabec TR, McNamara JA, Eagle RC Jr, Tasman W: Cryotherapy for retinopathy of prematurity: a histopathologic comparison of a treated and untreated eye. Ophthalmic Surg 1994;25:38-41.
16 Akkoyun I, Oto S, Yilmaz G, Gurakan B, Tarcan A, Anuk D, Akgun S, Akova YA: Risk factors in the development of mild and severe retinopathy of prematurity. J AAPOS 2006; 10:449-453.

17 Milligan DW: Failure of autoregulation and intraventricular haemorrhage in preterm infants. Lancet 1980;1:896-898.

18 Hardy P, Abran D, Li DY, Fernandez H, Varma DR, Chemtob S: Free radicals in retinal and choroidal blood flow autoregulation in the piglet: interaction with prostaglandins. Invest Ophthalmol Vis Sci 1994;35:580-591.

19 Hardy P, Lamireau D, Hou X, Dumont I, Abran D, Nuyt AM, Varma DR, Chemtob S: Major role for neuronal NO synthase in curtailing choroidal blood flow autoregulation in newborn pig. J Appl Physiol 2001;91:16551662 .

20 Checchin D, Hou X, Hardy P, Abran D, Najarian T, Beauchamp MH, Bernier SG, Gobeil F Jr, Quiniou C, Varma DR, Chemtob S: PGE2-mediated eNOS induction in prolonged hypercapnia. Invest Ophthalmol Vis Sci 2002;43:1558-1566.

-21 Holmes JM, Zhang S, Leske DA, Lanier WL: Carbon dioxide-induced retinopathy in the neonatal rat. Curr Eye Res 1998;17:608-616.

22 Alon T, Hemo I, Itin A, Pe'er J, Stone J, Keshet E: Vascular endothelial growth factor acts as a survival factor for newly formed retinal vessels and has implications for retinopathy of prematurity. Nat Med 1995;1:1024-1028.

23 Chen J, Connor KM, Aderman CM, Smith LE: Erythropoietin deficiency decreases vascular stability in mice. J Clin Invest 2008;118: 526-533. 
24 Hellstrom A, Perruzzi C, Ju M, Engstrom E, Hard AL, Liu JL, Albertsson-Wikland K, Carlsson B, Niklasson A, Sjodell L, LeRoith D, Senger DR, Smith LE: Low IGF-I suppresses VEGF-survival signaling in retinal endothelial cells: direct correlation with clinical retinopathy of prematurity. Proc Natl Acad Sci USA 2001;98:5804-5808.

- 25 Connor KM, SanGiovanni JP, Lofqvist C, Aderman CM, Chen J, Higuchi A, Hong S, Pravda EA, Majchrzak S, Carper D, Hellstrom A, Kang JX, Chew EY, Salem N Jr, Serhan CN, Smith LE: Increased dietary intake of omega-3-polyunsaturated fatty acids reduces pathological retinal angiogenesis. Nat Med 2007;13:868-873.

26 Hardy P, Peri KG, Lahaie I, Varma DR, Chemtob S: Increased nitric oxide synthesis and action preclude choroidal vasoconstriction to hyperoxia in newborn pigs. Circ Res 1996;79:504-511.

27 Hardy P, Beauchamp M, Sennlaub F, Gobeil F Jr, Tremblay L, Mwaikambo B, Lachapelle $P$, Chemtob S: New insights into the retinal circulation: inflammatory lipid mediators in ischemic retinopathy. Prostaglandins Leukot Essent Fatty Acids 2005;72:301-325.

28 Balazy M, Chemtob S: Trans-arachidonic acids: new mediators of nitro-oxidative stress. Pharmacol Ther 2008;119:275-290.

29 Abran D, Varma DR, Chemtob S: Increased thromboxane-mediated contractions of retinal vessels of newborn pigs to peroxides. Am J Physiol 1995;268:H628-H632.

30 Beauchamp MH, Sennlaub F, Speranza G, Gobeil F Jr, Checchin D, Kermorvant-Duchemin E, Abran D, Hardy P, Lachapelle P, Varma DR, Chemtob S: Redox dependent effects of nitric oxide on microvascular integrity in oxygen-induced retinopathy. Free Radic Biol Med 2004;37:1885-1894.

31 Checchin D, Sennlaub F, Sirinyan M, Brault S, Zhu T, Kermorvant-Duchemin E, Hardy P, Balazy M, Chemtob S: Hypercapnia prevents neovascularization via nitrative stress. Free Radic Biol Med 2006;40:543-553.

- 32 Gu X, El-Remessy AB, Brooks SE, Al-Shabrawey $M$, Tsai NT, Caldwell RB: Hyperoxia induces retinal vascular endothelial cell apoptosis through formation of peroxynitrite. Am J Physiol Cell Physiol 2003;285: C546-C554.

- 33 Brooks SE, Gu X, Samuel S, Marcus DM, Bartoli M, Huang PL, Caldwell RB: Reduced severity of oxygen-induced retinopathy in eNOS-deficient mice. Invest Ophthalmol Vis Sci 2001;42:222-228.

34 Kermorvant-Duchemin E, Sennlaub F, Sirinyan M, Brault S, Andelfinger G, Kooli A, Germain S, Ong H, d'Orleans-Juste P, Gobeil F Jr, Zhu T, Boisvert C, Hardy P, Jain K, Falck JR, Balazy M, Chemtob S: Trans-arachidonic acids generated during nitrative stress induce a thrombospondin-1-dependent microvascular degeneration. Nat Med 2005;11: 1339-1345.
35 Penn JS, Tolman BL, Bullard LE: Effect of a watersoluble vitamin $\mathrm{E}$ analog, trolox $\mathrm{C}$, on retinal vascular development in an animal model of retinopathy of prematurity. Free Radic Biol Med 1997;22:977-984.

-36 Niesman MR, Johnson KA, Penn JS: Therapeutic effect of liposomal superoxide dismutase in an animal model of retinopathy of prematurity. Neurochem Res 1997;22:597605.

37 Beauchamp MH, Martinez-Bermudez AK, Gobeil F Jr, Marrache AM, Hou X, Speranza G, Abran D, Quiniou C, Lachapelle P, Roberts J 2nd, Almazan G, Varma DR, Chemtob $S$ : Role of thromboxane in retinal microvascular degeneration in oxygen-induced retinopathy. J Appl Physiol 2001;90:2279-2288.

38 Hou X, Gobeil F Jr, Peri K, Speranza G, Marrache AM, Lachapelle $P$, Roberts J 2nd, Varma DR, Chemtob S, Ellis EF: Augmented vasoconstriction and thromboxane formation by $15-\mathrm{F}(2 \mathrm{t})$-isoprostane (8-iso-prostaglan$\operatorname{din} \mathrm{F}(2 \mathrm{alpha})$ ) in immature pig periventricular brain microvessels. Stroke 2000;31:516524.

-39 Zghibeh CM, Raj Gopal V, Poff CD, Falck JR, Balazy M: Determination of trans-arachidonic acid isomers in human blood plasma. Anal Biochem 2004;332:137-144.

40 Snyder F: Platelet-activating factor and related acetylated lipids as potent biologically active cellular mediators. Am J Physiol 1990; 259:C697-C708.

-41 Beauchamp MH, Marrache AM, Hou X, Gobeil F Jr, Bernier SG, Lachapelle P, Abran D, Quiniou C, Brault S, Peri KG, Roberts J 2nd, Almazan G, Varma DR, Chemtob S: Plateletactivating factor in vasoobliteration of oxygen-induced retinopathy. Invest Ophthalmol Vis Sci 2002;43:3327-3337.

-42 Hou X, Gobeil F Jr, Marrache AM, Quiniou C, Brault S, Checchin D, Bernier SG, Sennlaub F, Joyal JS, Abran D, Peri K, Varma DR, Chemtob S: Increased platelet-activating factor induced periventricular brain microvascular constriction associated with immaturity. Am J Physiol Regul Integr Comp Physiol 2003;284:R928-R935.

43 Brault S, Gobeil F Jr, Fortier A, Honoré JC, Joyal JS, Sapieha PS, Kooli A, Martin E, Hardy P, Ribeiro-da-Silva A, Peri K, Lachapelle P, Varma D, Chemtob S: Lysophosphatidic acid induces endothelial cell death by modulating the redox environment. Am J Physiol Regul Integr Comp Physiol 2007;292:R1174R1183.

-44 Liu JP, Baker J, Perkins AS, Robertson EJ, Efstratiadis A: Mice carrying null mutations of the genes encoding insulin-like growth factor I (IGF-1) and type 1 IGF receptor (IGF1R). Cell 1993;75:59-72.

45 Langford K, Nicolaides K, Miell JP: Maternal and fetal insulin-like growth factors and their binding proteins in the second and third trimesters of human pregnancy. Hum Reprod 1998;13:1389-1393.
-46 Lineham JD, Smith RM, Dahlenburg GW, King RA, Haslam RR, Stuart MC, Faull L: Circulating insulin-like growth factor I levels in newborn premature and full term infants followed longitudinally. Early Hum Dev 1996;13:37-46.

47 Smith L: Essential role of growth hormone in ischemia-induced retinal neovascularization. Science 1997;276:1706-1709.

48 Smith LE, Shen W, Perruzzi C, Soker S, Kinose F, Xu X, Robinson G, Driver S, Bischoff J, Zhang B, Schaeffer JM, Senger DR: Regulation of vascular endothelial growth factordependent retinal neovascularization by insulin-like growth factor-1 receptor. Nat Med 1999;5:1390-1395.

- 49 Hellstrom A, Engstrom E, Hard AL, Albertsson-Wikland $\mathrm{K}$, Carlsson B, Niklasson A, Löfquist C, Svensson E, Holm S, Ewald U, Holmström G, Smith LE: Postnatal serum insulin-like growth factor I deficiency is associated with retinopathy of prematurity and other complications of premature birth. Pediatrics 2003;112:1016-1020.

-50 Lofqvist C, Chen J, Connor KM, Smith AC, Aderman CM, Liu N, Pintar JE, Ludwig T, Hellstrom A, Smith LE: IGFBP3 suppresses retinopathy through suppression of oxygeninduced vessel loss and promotion of vascular regrowth. Proc Natl Acad Sci USA 2007; 104:10589-10594.

51 Hansen-Pupp I, Engstrom E, Niklasson A, Berg AC, Fellman V, Lofqvist C, Hellström A, Ley D: Fresh frozen plasma as a source of exogenous insulin-like growth factor I in the extremely preterm infant. J Clin Endocrinol Metab 2009;94:477-482.

- 52 Lofqvist C, Niklasson A, Engstrom E, Friberg LE, Camacho-Hubner C, Ley D, Borg J, Smith LE, Hellström A: A pharmacokinetic and dosing study of intravenous insulin-like growth factor-I and IGF-binding protein-3 complex to preterm infants. Pediatr Res 2009;65:574-579.

53 Vanhaesebrouck S, Daniels H, Moons L, Vanhole C, Carmeliet P, De Zegher F: Oxygen-induced retinopathy in mice: amplification by neonatal IGF-1 deficit and attenuation by IGF-1 administration. Pediatr Res 2009;65:307-310.

54 Miao HQ, Soker S, Feiner L, Alonso JL, Raper JA, Klagsbrun M: Neuropilin-1 mediates collapsin-1/semaphorin III inhibition of endothelial cell motility: functional competition of collapsin-1 and vascular endothelial growth factor-165. J Cell Biol 1999; 146:233242 .

55 Klagsbrun M, Eichmann A: A role for axon guidance receptors and ligands in blood vessel development and tumor angiogenesis. Cytokine Growth Factor Rev 2005; 16:535548 . 
-56 Joyal JS, Sitaras N, Binet F, Rivera JC, Stahl A, Zaniolo K, Shao Z, Polosa A, Zhu T, Hamel D, Djavari M, Kunik D, Honoré JC, Picard E, Zabeida A, Varma DR, Hickson G, Mancini J, Klagsbrun M, Costantino S, Beauséjour C, Lachapelle P, Smith LE, Chemtob S, Sapieha P: Ischemic neurons prevent vascular regeneration of neural tissue by secreting semaphorin 3A. Blood 2011; 117:6024-6035.

-57 Fukushima Y, Okada M, Kataoka H, Hirashima M, Yoshida Y, Mann F, Gomi F, Nishida K, Nishikawa S, Uemura A: Sema3EPlexinD1 signaling selectively suppresses disoriented angiogenesis in ischemic retinopathy in mice. J Clin Invest 2011;121: 1974-1985.

58 Gariano RF, Gardner TW: Retinal angiogenesis in development and disease. Nature 2005;438:960-966.

-59 Sapieha P, Sirinyan M, Hamel D, Zaniolo K, Joyal JS, Cho JH, Honoré JC, KermorvantDuchemin E, Varma DR, Tremblay S, Leduc M, Rihakova L, Hardy P, Klein WH, Mu X, Mamer O, Lachapelle P, Di Polo A, Beauséjour C, Andelfinger G, Mitchell G, Sennlaub F, Chemtob S: The succinate receptor GPR91 in neurons has a major role in retinal angiogenesis. Nat Med 2008;14:1067-1076.

-60 He W, Miao FJ, Lin DC, Schwandner RT, Wang Z, Gao J, Chen JL, Tian H, Ling L: Citric acid cycle intermediates as ligands for orphan G-protein-coupled receptors. Nature 2004;429:188-193.
61 Sood BG, Madan A, Saha S, Schendel D, Thorsen P, Skogstrand K, Hougaard D, Shankaran S, Carlo W, NICHD Neonatal Research Network: Perinatal systemic inflammatory response syndrome and retinopathy of prematurity. Pediatr Res 2010;67:394400.

62 Sato T, Kusaka S, Shimojo H, Fujikado T: Simultaneous analyses of vitreous levels of 27 cytokines in eyes with retinopathy of prematurity. Ophthalmology 2009;116:2165-2169.

63 Dubois RN, Abramson SB, Crofford L, Gupta RA, Simon LS, Van De Putte LB, Lipsky PE: Cyclooxygenase in biology and disease. FASEB J 1998;12:1063-1073.

64 Sennlaub F, Valamanesh F, Vazquez-Tello A El-Asrar AM, Checchin D, Brault S, Gobeil F, Beauchamp MH, Mwaikambo B, Courtois Y, Geboes K, Varma DR, Lachapelle P, Ong $\mathrm{H}$, Behar-Cohen F, Chemtob S: Cyclooxygenase-2 in human and experimental ischemic proliferative retinopathy. Circulation 2003;108:198-204.

65 Weitz D, Weintraub H, Fisher E, Schwartz bard AZ: Fish oil for the treatment of cardiovascular disease. Cardiol Rev 2010;18:258263.

66 Mayurasakorn K, Williams JJ, Ten VS, Deckelbaum RJ: Docosahexaenoic acid: brain accretion and roles in neuroprotection after brain hypoxia and ischemia. Curr Opin Clin Nutr Metab Care 2011;14:158-167.

67 Jeffrey BG, Weisinger HS, Neuringer M, Mitchell DC: The role of docosahexaenoic acid in retinal function. Lipids 2001;36:859871.

-68 SanGiovanni JP, Parra-Cabrera S, Colditz GA, Berkey CS, Dwyer JT: Meta-analysis of dietary essential fatty acids and long-chain polyunsaturated fatty acids as they relate to visual resolution acuity in healthy preterm infants. Pediatrics 2000;105:1292-1298.
69 Sapieha P, Stahl A, Chen J, Seaward MR, Willett KL, Krah NM, Dennison RJ, Connor KM, Aderman CM, Liclican E, Carughi A, Perelman D, Kanaoka Y, Sangiovanni JP, Gronert K, Smith LE: 5-Lipoxygenase metabolite 4-HDHA is a mediator of the antiangiogenic effect of $\omega-3$ polyunsaturated fatty acids. Sci Transl Med 2011;3:69ra12.

70 Pawlik D, Lauterbach R, Turyk E: Fish-oil fat emulsion supplementation may reduce the risk of severe retinopathy in VLBW infants. Pediatrics 2011;127:223-228.

71 Chew EY: Fatty acids and retinopathy. N Engl J Med 2011;19;364:1970-1971.

72 Micieli JA, Surkont M, Smith AF: A systematic analysis of the off-label use of bevacizumab for severe retinopathy of prematurity. Am J Ophthalmol 2009;148:536-543.

$>73$ Chen ML, Guo L, Smith LE, Dammann CE, Dammann O: High or low oxygen saturation and severe retinopathy of prematurity: a meta-analysis. Pediatrics 2010;125:e1483e1492.

74 Raju TN, Langenberg P, Bhutani V, Quinn GE: Vitamin E prophylaxis to reduce retinopathy of prematurity: a reappraisal of published trials. J Pediatr 1997;131:844-850.

75 Berger TM, Rifai N, Avery ME, Frei B: Vitamin $\mathrm{C}$ in premature and full-term human neonates. Redox Rep 1996;2:257-262.

76 Otani A, Kinder K, Ewalt K, Otero FJ, Schimmel P, Friedlander M: Bone marrow-derived stem cells target retinal astrocytes and can promote or inhibit retinal angiogenesis. Nat Med 2002;8:1004-1010. 